\title{
Cyclopolymers as Liquid Membrane Carriers
}

Emanuela Cagnoni, ${ }^{\mathrm{a}}$ Dario Pasini, ${ }^{* a}$ Alessandro Galbiati, ${ }^{\mathrm{b}}$ Marina Ricci, ${ }^{a}$ Pier Paolo Righetti ${ }^{\mathrm{a}}$ a) Department of Organic Chemistry, University of Pavia,Viale Taramelli, 10 - 27100 Pavia - Italy.

b)NPT s.r.l.-Viale Zanotti, 90 - I-27027 Gropello Cairoli (PV) - Italy

dario.pasini@unipv.it

\section{SUPPLEMENTARY INFORMATION AVAILABLE}

Table S1. Molar absorbivities at $380 \mathrm{~nm}$ in $\mathrm{MeCN}$ for the different alkaline metal ion picrate salts at $25^{\circ} \mathrm{C}$. The values reported in the literature were 16900 for all the salts reported here (ref. 11 in the main text).

\begin{tabular}{cc}
\hline Picrate Salt & $\mathbf{3 8 0}$ \\
\hline $\mathbf{L i}^{+}$-picrate & 16.700 \\
$\mathbf{N a}^{+}$-picrate & 18.900 \\
$\mathbf{K}^{+}$-picrate & 15.400 \\
$\mathbf{C s}^{+}$-picrate & 17.000 \\
\hline
\end{tabular}


Table S2. Initial transport rates of the alkaline metal picrate salts from the aqueous source phase to the receiving phase through a liquid organic membrane, mediated by the carrier indicated in column 1.

\begin{tabular}{cccc}
\hline Carrier $\backslash \mathbf{M}^{+}$ & Sodium & Potassium & Cesium \\
\hline None & - & - & 0 \\
$\mathbf{4}$ & 0,028 & 0,0171 & 0,0078 \\
$\mathbf{5}$ & 0,0182 & 0,689 & 0,2182 \\
$\mathbf{6}$ & 0,0116 & 0,0256 & 0,0229 \\
\hline
\end{tabular}


Figure S1. Linear regressions of the data for the initial transport rates for the alkaline metal ions using monomer $\mathbf{5}$ as the carrier.

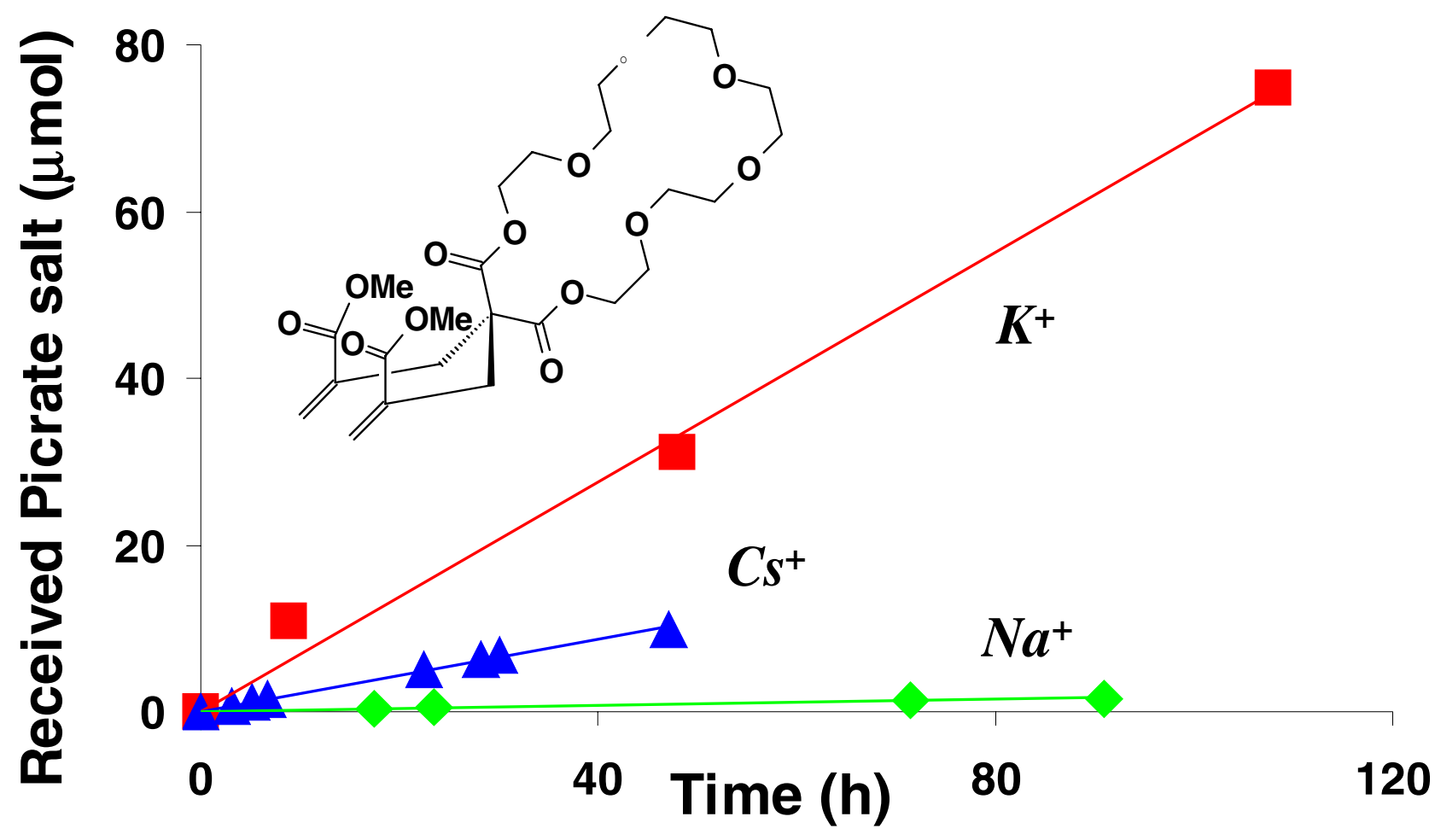


Figure S2. Gel permeation chromatograms for polymer 7, after precipitation in cyclohexane, relative to entries 5 (bottom) and 6 (top), Table 1.

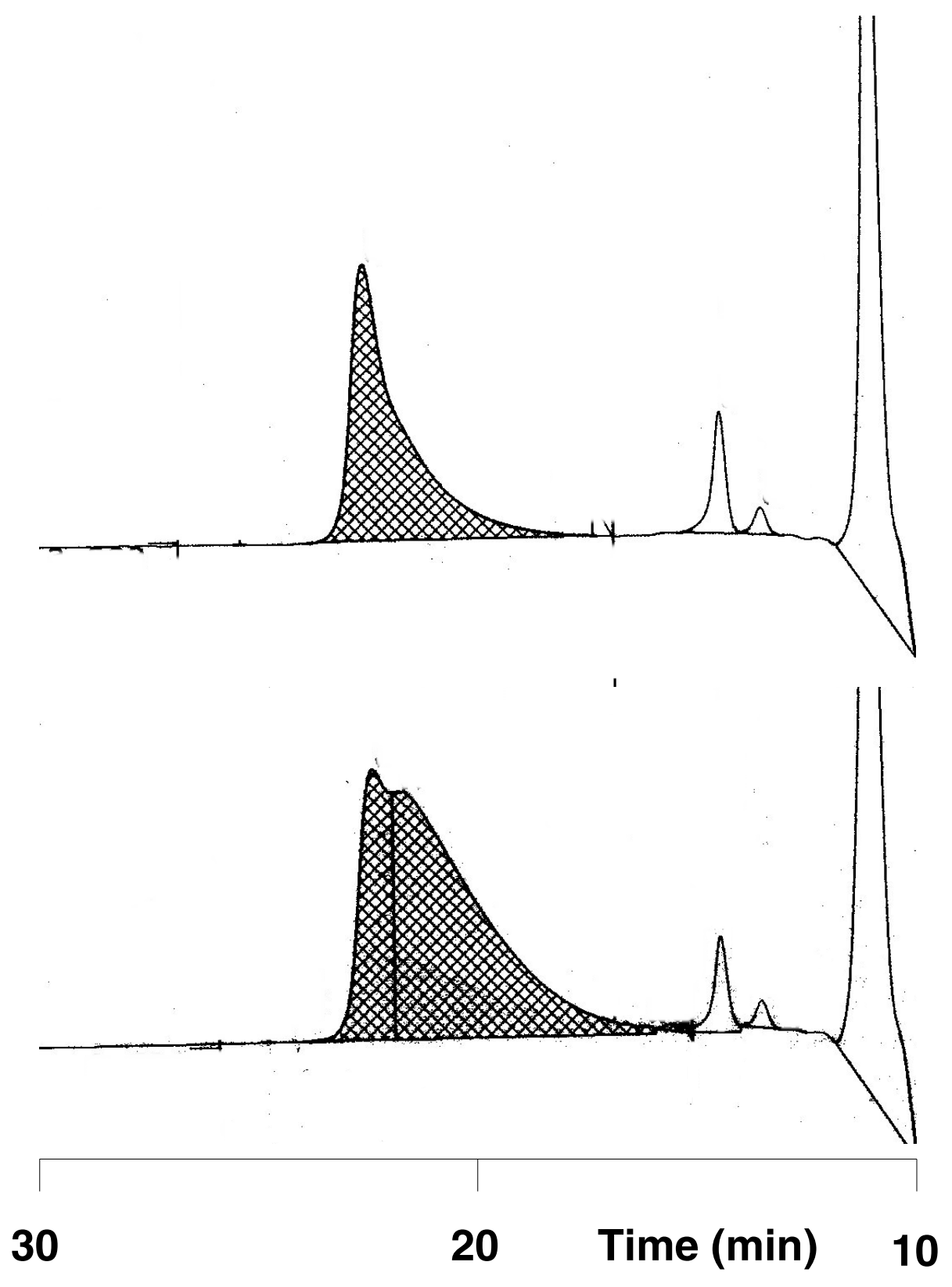

